\title{
Doppler optical coherence tomography for energy seal evaluation and comparison to visual evaluation (Erratum)
}

\author{
Andrew J. Marques \\ Robnier Reyes \\ Christopher R. Pasarikovski \\ Chaoliang Chen \\ Joel Ramjist \\ Xijia $\mathrm{Gu}$ \\ Victor Yang
}

Andrew J. Marques, Robnier Reyes, Christopher R. Pasarikovski, Chaoliang Chen, Joel Ramjist, Xijia Gu, Victor Yang, "Doppler optical coherence tomography for energy seal evaluation and 


\title{
Doppler optical coherence tomography for energy seal evaluation and comparison to visual evaluation (Erratum)
}

\author{
Andrew J. Marques, ${ }^{\text {a }}$ Robnier Reyes, ${ }^{\text {a }}$ Christopher R. Pasarikovski, ${ }^{\text {b }}$ \\ Chaoliang Chen, ${ }^{a}$ Joel Ramjist, ${ }^{a}$ Xijia Gu, ${ }^{\mathrm{c}}$ and Victor Yang, ${ }^{\mathrm{a}, \mathrm{d}, \mathrm{e}}$ \\ ${ }^{a}$ Ryerson University, Bioengineering and Biophotonics Laboratory, Department of Electrical, \\ Computer, and Biomedical Engineering, Toronto, Ontario, Canada \\ ${ }^{b}$ University of Toronto, Division of Neurosurgery, Department of Surgery, Toronto, \\ Ontario, Canada \\ ${ }^{\mathrm{c}}$ Ryerson University, Department of Electrical, Computer, and Biomedical Engineering, \\ Toronto, Ontario, Canada \\ ${ }^{\mathrm{d}}$ Sunnybrook Health and Sciences Center, Division of Neurosurgery, Toronto, Ontario, Canada \\ ${ }^{\mathrm{e}}$ University of Toronto, Division of Neurosurgery, Faculty of Medicine, Toronto Ontario, Canada
}

[DOI: 10.1117/1.JBO.25.4.049801]

This article [J. Biomed. Optics, 25(3), 035003 (2020), doi: 10.1117/1.JBO.25.3.035003] was originally published online on 9 March 2020 with an error in the spelling of an author's surname. The correct spelling is Pasarikovski.

This article was corrected on 9 April 2020. 